Check for updates

Cite this: RSC Adv., 2019, 9, 28345

\title{
Revealing the role of the 1T phase on the adsorption of organic dyes on $\mathrm{MoS}_{2}$ nanosheets $\uparrow$
}

\author{
Asmaa M. Omar, ${ }^{a}$ Ossama I. Metwalli, ${ }^{a}$ Mohamed R. Saber, ${ }^{b}$ Gomaa Khabiri, ${ }^{a}$ \\ Mohamed E. M. Ali, ${ }^{c}$ Arafa Hassen, ${ }^{a}$ Mostafa M. H. Khalil, (D) ${ }^{d}$ Ahmed A. Maarouf ${ }^{\star e}$ \\ and Ahmed S. G. Khalil (iD)*a
}

Herein, different phases of $\mathrm{MoS}_{2}$ nanosheets were synthesized, characterized and tested for dye removal from water. The influence of the $\mathrm{MoS}_{2}$ phases as well as the $1 \mathrm{~T}$ concentration on the adsorption performance of organic dyes $\mathrm{MO}, \mathrm{RhB}$ and $\mathrm{MB}$ was deeply investigated. The results revealed that the $1 \mathrm{~T}$-rich $\mathrm{MoS}_{2}$ nanosheets have superior adsorption performance compared to other $2 \mathrm{H}$ and $3 \mathrm{R}$ phases. The kinetic results of the adsorption process demonstrate that the experimental data followed the pseudo-second order equation. Meanwhile, the adsorption of dyes over the obtained materials was fitted with several isotherm models. The Langmuir model gives the best fitting to the experimental data with maximum a adsorption capacity of $787 \mathrm{mg} \mathrm{g}^{-1}$. The obtained capacity is significantly higher than that of all previous reports for similar $\mathrm{MoS}_{2}$ materials. Computational studies of the $2 \mathrm{H}$ and $1 \mathrm{~T} / 2 \mathrm{H}-\mathrm{MoS}_{2}$ phases showed that the structural defects present at the $1 \mathrm{~T} / 2 \mathrm{H}$ grain boundaries enhance the binding of hydroxide and carboxyl groups to the $\mathrm{MoS}_{2}$ surface which in turn increase the adsorption properties of the $1 \mathrm{~T} / 2 \mathrm{H}-\mathrm{MoS}_{2}$ phase.

Received 15th July 2019

Accepted 29th August 2019

DOI: $10.1039 / \mathrm{c} 9 \mathrm{ra0} 5427 \mathrm{~h}$

rsc.li/rsc-advances layers of hybridized $\mathrm{MoS}_{2}$ (ref. 17-19) with 1T-phase concentration up to $70 \% .^{5,18}$

Treatment of organic pollutants using $\mathrm{MoS}_{2}$ materials via adsorption or photocatalytic degradation has been extensively studied. ${ }^{1-4,6,7,12,20}$ However, several contradicting reports on this topic can be found due to the very delicate nature of the material. ${ }^{\mathbf{1 - 4 , 6 - 9}}$ The electronic structure of the material and its activity are quite sensitive to several parameters including the molybdenum local coordination, surface defects, crystal phase, degree of exfoliation, and the size and morphology of the nanosheets. For instance, several reports claimed fast and efficient adsorption of different organic dyes using $\mathrm{MoS}_{2}$ composites..$^{\mathbf{1 - 4 , 6 , 2 1 - 2 8}} \mathrm{He} \mathrm{Li}$ et al. ${ }^{29}$ used porous $\mathrm{MoS}_{2}$ nanosheets to efficiently remove $\mathrm{RhB}, \mathrm{MB}$ and $\mathrm{MO}$ with adsorption capacities of about $163.0 \mathrm{mg} \mathrm{g}^{-1}, 499.0 \mathrm{mg} \mathrm{g}^{-1}$ and $125.1 \mathrm{mg}$ $\mathrm{g}^{-1}$ at $420 \mathrm{~min}$, respectively. Also, Xiu and co-workers ${ }^{21}$ found that the $\mathrm{MoS}_{2}$ exhibits good and fast performance for removal of MB from aqueous solution, with an adsorption capacity of $146.43 \mathrm{mg} \mathrm{g}^{-1}$ in $6 \mathrm{~min}$. However, in another study the authors reported no adsorptive capabilities for their $\mathrm{MoS}_{2}$ samples. ${ }^{20}$ Xie and co-workers ${ }^{30}$ reported low adsorption towards MB and MO with adsorption capacity of about 70 and $25 \mathrm{mg} \mathrm{g}^{-1}$ respectively.

The high adsorption capacity reported for some $\mathrm{MoS}_{2}$ nanosheets and $\mathrm{MoS}_{2}$ based heterostructures were ascribed to the high surface area of $\mathrm{MoS}_{2}$ and $\mathrm{MoS}_{2}$-composites, which increases the number of active sites per unit volume and consequently leads to high adsorption capacity. ${ }^{31}$ However, in other studies, ${ }^{7,32}$ it has been demonstrated that the surface $\dagger$ Electronic supplementary information (ESI) available. See DOI:

$10.1039 / \mathrm{c} 9 \mathrm{ra} 05427 \mathrm{~h}$
${ }^{a}$ Environmental and Smart Technology Group (ESTG), Physics Department, Faculty of (Fayoum University,63514 Fayoum, Eoypt.E-mail:asg05@fayoum.edu.e. 'Water Pollution Research Department, National Research Centre, 33 El Bohouth St. P.O. 12622, Giza, Egypt

Cairo, Egypt

${ }^{e}$ Department of Physics, IRMC, Imam Abdulrahman Bin Faisal University, Saudia Arabia.E-mail: amaarouf@iau.edu.sa 
area has no effect on the adsorption activity. Whereas an effect of intermolecular interaction, such as van der Waals and electrostatic attraction, ${ }^{7}$ or the existence of highly reactive $\mathrm{OH}$ radical groups on the $\mathrm{MoS}_{2}$ surface ${ }^{33}$ was proposed. To the best of our knowledge, there are no reports that provide a clear correlation between the high adsorption performance of $\mathrm{MoS}_{2}$ with the material surface activity and its phase composition.

Computational studies of the adsorption properties of twodimensional materials have been extensively performed, so as to understand the role of various parameters controlling molecular adsorption on their surfaces. Graphene, being a 2D material with relative ease of fabrication was extensively studied. $^{34-36}$ The surface structure, defects, and functionalization play an important role. In addition, various properties of the adsorbents (such as geometrical configuration, hydrophobicity, size, and substituent chemical groups) were investigated. ${ }^{37,38}$

With the progress in fabricating $2 \mathrm{D} \mathrm{MoS}_{2}$ nanosheets, molecular adsorption on its surface have been recently computationally investigated, where defects arising from Mo or $S$ vacancies can lead to an enhancement of its adsorption and catalytic properties. ${ }^{39,40}$ Edges of $\mathrm{MoS}_{2}$ nanoparticles, where the atomic coordination of the Mo and $\mathrm{S}$ atoms is different from the bulk, provide active sites that can anchor various functional groups, adsorb various gases, and catalyse hydrogen evolution reactions. $^{33,41,42}$ Mixed phase $1 \mathrm{~T} / 2 \mathrm{H}$ structures have been experimentally and computationally studied for various applications, including solar thermal water purification. ${ }^{43}$ The $1 \mathrm{~T} / 2 \mathrm{H}$ in plane phase hybridization offers a $\mathrm{MoS}_{2}$ structure with lower sheet resistance $\left(<1 \mathrm{k} \Omega \mathrm{sq}^{-1}\right)$ and high specific capacitance two orders of magnitude higher than the pure $2 \mathrm{H}$ phase. ${ }^{\mathbf{4 4}}$ Electronic studies of hybridized phases revealed that the presence of $1 \mathrm{~T}$ islands in a $2 \mathrm{H} \mathrm{MoS}$ sheet induces some structural defects at the grain boundaries of the $1 \mathrm{~T}$ phase, where the $\mathrm{S}$ and Mo sublattices suffer some local stresses. These manifests themselves as changes in the $2 \mathrm{H}$ electronic spectrum, leading to the emergence of midgap states, and causing an increase in the electronic conductivity of the hybrid phase compared to the pure $2 \mathrm{H}$ one. In addition, the structural defects at the $1 \mathrm{~T}$ boundary alter the electrostatic landscape of the system, inviting an investigation of molecular adsorption in these regions.

In our recent work, ${ }^{5}$ hybridized phases of $\mathrm{MoS}_{2}$ were synthesized using hydrothermal method with the reactor filling ratio acting as the controlling factor of the $1 \mathrm{~T}$ content of the material. The results of the photocatalytic degradation of MO using these materials under visible light strongly correlated the photocatalytic activity of $\mathrm{MoS}_{2}$ materials to their phases with a significantly improved performance of $1 \mathrm{~T}$ containing phases. Our calculations suggested that the introduction of $1 \mathrm{~T}$ sites into the $2 \mathrm{H}$ layers of the material lead to surface distortions and mid-gap states which improve the conductivity and catalytic activity.

In this report, the adsorptive properties of the mixed phase $\mathrm{MoS}_{2}$ nanosheets $(1 \mathrm{~T} / 2 \mathrm{H}, 2 \mathrm{H}$ and $3 \mathrm{R})$ have been explored. The adsorption behaviour of the samples has been thoroughly investigated using $\mathrm{MB}, \mathrm{RhB}$ and $\mathrm{MO}$ organic dyes in order to determine the effect of the sample phase on the adsorption performance. The conditions of adsorption process have been optimized in order to conduct detailed kinetics and thermodynamics studies. We also present first principle calculations of the adsorption properties of the different phases of $\mathrm{MoS}_{2}$ nanosheets, where we study the effects of the $1 \mathrm{~T} / 2 \mathrm{H}$ domain boundaries.

\section{Experimental}

\subsection{Chemicals}

Methylene blue (MB); $\left(\mathrm{C}_{16} \mathrm{H}_{18} \mathrm{ClN}_{3} \mathrm{~S}\right)$, methyl orange; (MO) $\left(\mathrm{C}_{14} \mathrm{H}_{14} \mathrm{~N}_{3} \mathrm{NaO}_{3} \mathrm{~S}\right)$ and rhodamine $\mathrm{B}(\mathrm{RhB}) ;\left(\mathrm{C}_{28} \mathrm{H}_{31} \mathrm{ClN}_{2} \mathrm{O}_{3}\right)$ were purchased from Sigma Aldrich. Ammonium molybdate $\left(\left(\mathrm{NH}_{4}\right)_{6} \mathrm{Mo}_{7} \mathrm{O}_{24} \cdot 4 \mathrm{H}_{2} \mathrm{O}\right)$ was purchased from SD Fine Chem limited, India. Thiourea $\left(\mathrm{CH}_{4} \mathrm{~N}_{2} \mathrm{~S}\right)$ was purchased from Loba Chemie, India. All chemicals were of analytical grade and used without further purification. The different concentrations of MB, MO, and RhB solutions were prepared by dissolving the required amount of these dyes in deionized water.

\subsection{Synthesis of $\mathrm{MoS}_{2}$}

Four different samples (S1-S4) of $\mathrm{MoS}_{2}$ nanosheets were prepared using the hydrothermal method. For S1, $2.47 \mathrm{~g}$ of $\left(\mathrm{NH}_{4}\right)_{6} \mathrm{Mo}_{7} \mathrm{O}_{24} \cdot 4 \mathrm{H}_{2} \mathrm{O}$ and $0.76 \mathrm{~g}$ of $\mathrm{CS}\left(\mathrm{NH}_{2}\right)_{2}$ were dissolved in $60 \mathrm{~mL}$ of DI water under constant stirring. The whole mixture was transferred into a $134 \mathrm{~mL}$ Teflon-lined stainless-steel autoclave. The autoclave was kept in an oven at $200{ }^{\circ} \mathrm{C}$ for $24 \mathrm{~h}$, then left to cool down to room temperature. The resulting black precipitate was collected by centrifugation, washed three times with distilled water then with ethanol, and dried in an oven for $12 \mathrm{~h}$ at $80^{\circ} \mathrm{C}$. To obtain the different phases, a variation of the reactor filling ratio $(75 \%, \mathrm{~S} 2)$ and molar ratio of Mo and $\mathrm{S} 1: 25,75 \%$ (S3) were used. Further thermal treatment of $1 \mathrm{~T} / 3 \mathrm{R}-\mathrm{MoS}_{2}$ in a tube furnace (Carbolite) at $800{ }^{\circ} \mathrm{C}$ under $\mathrm{Ar}$ for 2 hours resulted in $2 \mathrm{H}-\mathrm{MoS}_{2}(\mathrm{~S} 4)$. The ratios between IT and $2 \mathrm{H} / 3 \mathrm{R}$ phases in the samples were estimated from XPS analyses. $^{5}$

\subsection{Materials characterization}

The morphologies of the prepared samples were measured using scanning electron microscope (Zeiss Sigma 500 VP, equipped with Oxford EDS detector). HRTEM images were obtained using JOEL $2100 \mathrm{~F}$ at $200 \mathrm{kV}$. X-ray diffraction patterns were collected using $\mathrm{Cu} \mathrm{K} \alpha$ monochromatic radiation $\left(\mathrm{K}_{1 / 4}\right.$ 1.54056) at room temperature on a 202964 Panalytical Empryan diffractometer. Brunauer-Emmet-Teller (BET) surface area was analysed using a TriStar instrument with nitrogen adsorption at $77 \mathrm{~K}$ using the Barrett-Joyner-Halenda (BJH) method. The zeta potential and size at different $\mathrm{pH}$ was performed using Nano-ZS (Malvern, UK).

\subsection{Adsorption experiments}

The adsorption experiments were performed in the dark at room temperature in order to eliminate any possible 
photocatalytic degradation of the used dyes. The adsorption behaviour of the prepared samples was investigated by monitoring the reduction of $\mathrm{MB}, \mathrm{RhB}$ and $\mathrm{MO}$ dyes in aqueous solutions $\left(20 \mathrm{mg} \mathrm{L}^{-1}\right)$. A calculated amount of the $\mathrm{MoS}_{2}$ samples was separately added to the above solutions with continuous magnetic stirring at $800 \mathrm{rpm}$. During the experiments, $3 \mathrm{~mL}$ of the supernatant was taken at different time intervals and analysed by UV-vis spectrophotometer (Agilent, Cary 60) at $\lambda_{\max }=$ 664, 554 and $464 \mathrm{~nm}$ for $\mathrm{MB}, \mathrm{RhB}$ and MO respectively, to determine the dye concentration. The sorbent was isolated via centrifugation. The adsorption percentage of dyes and adsorption capacity of $\mathrm{MoS}_{2}$ was calculated using the following equations:

$$
\begin{gathered}
R(\%)=\frac{C_{0}-C_{t}}{C_{0}} \times 100 \\
q_{t}\left(\mathrm{mg} \mathrm{g}^{-1}\right)=\left(C_{0}-C_{t}\right) V_{\mathrm{d}} / m_{\mathrm{A}}
\end{gathered}
$$

where, $C_{0}$ is the initial concentration of dye; $C_{t}$ is the dye concentration after $t$ minute; $V_{\mathrm{d}}$ is the volume of dye solution; $m_{\mathrm{A}}$ is the weight of $\mathrm{MoS}_{2}$.

\subsection{Computational methods}

All calculations were performed using the Quantum Espresso plane waves package based on density functional theory. ${ }^{45}$ The generalized gradient approximation was used in the scheme of Perdew-Burke-Ernzerhof for the exchange correlation functional, with ultrasoft pseudopotentials. A $6 \times 62 \mathrm{H}$ supercell was constructed, with a vacuum separation of $13 \AA$, to prevent the interaction between neighboring cells. All studied systems were structurally relaxed, until all atomic forces become less than $0.0001 \mathrm{Ry} \mathrm{bohr}^{-1}$. The self-consistent calculations were performed with an energy cut-off of $35 \mathrm{Ry}$, and with a $2 \times 2 \times 1$ Monkhorst-Pack $k$-mesh. ${ }^{46}$ The adsorption energies, $E_{\text {ad }}$, were calculated according to:

$$
E_{\mathrm{ad}}=E\left(\mathrm{MoS}_{2}\right)+E(\mathrm{X})-E\left(\mathrm{MoS}_{2}+\mathrm{X}\right)
$$

where $E\left(\mathrm{MoS}_{2}\right), E(\mathrm{X})$, and $E\left(\mathrm{MoS}_{2}+\mathrm{X}\right)$ were the total energies of the isolated $\mathrm{MoS}_{2}$ system, the isolated functional group X, and combined $\mathrm{MoS}_{2}+\mathrm{X}$ systems.

\section{Results and discussion}

$\mathrm{MoS}_{2}$ flower-like structures with different $1 \mathrm{~T}$ concentration were synthesized by hydrothermal reaction between ammonium molybdate and thiourea at $200^{\circ} \mathrm{C}$. The resulting phase is controlled through three factors: the molar ratio of Mo : S, the filling ratio of the reactor, and thermal treatment. Adjusting the ratio of Mo:S to $1: 5$ at $45 \%$ filling ratio of the reactor gives the hybridized S1, while the same molar ratio at $75 \%$ filling ratio gives S2. By increasing the filling of the reactor to $75 \%$ and using excess of sulphur with a Mo : S ratio of $1: 25$ we obtained S3. The thermal treatment of S3 at $800{ }^{\circ} \mathrm{C}$ under argon in a tube furnace gave pure $2 \mathrm{H}$ phase (S4). The obtained samples have been characterized using several analytical techniques. ${ }^{5}$

Fig. SI.1 $\uparrow$ shows the XRD patterns of the synthesized $\mathrm{MoS}_{2}$ samples. All the diffraction peaks of the prepared samples appeared noisy and broad, mainly due to the formation of nanosized $\mathrm{MoS}_{2}$ material. ${ }^{47} \mathrm{~S} 4$ exhibits five diffraction peaks at $13.7^{\circ}, 33.2^{\circ}, 39.3^{\circ}, 49.2^{\circ}$, and $58.6^{\circ}$, defined by the (002), (100), (103), (105), and (110) crystal planes, respectively. These results are in a good agreement with hexagonal $2 \mathrm{H}-\mathrm{MoS}_{2}$ pattern (PDF no. 00-024-0513). Whereas the diffraction patterns of S1-S3 indicate the existence of a hybridized $1 \mathrm{~T} / 2 \mathrm{H}$ and $1 \mathrm{~T} / 3 \mathrm{R}$ phases. ${ }^{48}$ SEM measurements of the $\mathrm{MoS}_{2}$ materials (Fig. 1A) showed micro-flowers consisting of aggregated $\mathrm{MoS}_{2}$ nanosheets for all samples which is typically reported for similar hydrothermally synthesized $\mathrm{MoS}_{2}$ materials. ${ }^{49}$ The EDS mapping (Fig. 1B-D) revealed the existence of Mo, S, and O in the layered $\mathrm{MoS}_{2}$ with uniform distribution, confirming the high quality of the prepared $\mathrm{MoS}_{2}$.

Fig. 2A shows the nitrogen adsorption-desorption isotherms curve of S1. The specific surface area of the $\mathrm{MoS}_{2}$ nanosheets, calculated by the multipoint BET method, was $6.18 \mathrm{~m}^{2} \mathrm{~g}^{-1}$. The specific area of the S3 and S4 was found to be 6.67 and $4.48 \mathrm{~m}^{2}$ $\mathrm{g}^{-1}$, respectively (Fig. SI.2†). No significant differences in the specific areas of the three samples were observed, which suggests that different adsorption responses of the samples cannot be attributed to the surface area of the $\mathrm{MoS}_{2}$ nanosheets. The adsorption of dyes onto the $\mathrm{MoS}_{2}$ adsorbent surface is strongly affected by the surface charge of the adsorbent. In addition, the adsorbent surface charge is significantly influenced by $\mathrm{pH}$ value. The zeta potential measurements of S1, S2 and S4 (Fig. 2B) reveal high negative surface charges in the range of $\mathrm{pH}=3-10$, which reflects the excellent stability of the $\mathrm{MoS}_{2}$ dispersions.

This negative surface charges are mainly due to $\mathrm{OH}$ and $\mathrm{COOH}$ functional groups on $\mathrm{MoS}_{2}$ surface $^{50}$ which act as surface active adsorption sites. ${ }^{51}$ The negative charge density on the surface of $\mathrm{MoS}_{2}$ nanosheets suggests that the interaction with adsorbates should be mainly electrostatic in nature with a possible affinity towards cationic dyes. ${ }^{52,53}$ Similar charge profiles at different $\mathrm{pH}$ were observed for $\mathrm{S} 2$ and $\mathrm{S} 4$. Fig. 2C shows the particle size of $\mathrm{S} 1, \mathrm{~S} 2$ and $\mathrm{S} 4$ aqueous dispersions. It can be seen that the $\mathrm{MoS}_{2}$ nanosheets of S1, S2 and S4 have small sizes (131 nm, $127 \mathrm{~nm}$ and $123 \mathrm{~nm}$ respectively) compared to previous reports. ${ }^{54}$ Very likely this is due to the better degree of exfoliation of $\mathrm{MoS}_{2}$ nanosheets.

\subsection{Adsorption performance}

In order to investigate the adsorption behaviour of the four prepared $\mathrm{MoS}_{2}$ samples with different phases, a certain dose of the samples $(50 \mathrm{mg})$ was added to $\mathrm{MB}$ aqueous solution $(100 \mathrm{~mL}, 20$ $\mathrm{ppm}$ ). The experiments were performed under dark conditions for $30 \mathrm{~min}$. Fig. SI. $3 \dagger$ shows a removal efficiency of $99 \%$ and adsorption capacity $40 \mathrm{mg} \mathrm{g}^{-1}$ for S1 (70\% 1T) compared to $87 \%, 34 \mathrm{mg} \mathrm{g}^{-1}$ for $\mathrm{S} 2(20 \% 1 \mathrm{~T}), 22 \%, 9 \mathrm{mg} \mathrm{g}^{-1}$ for S3 (1T/3R) and $11 \%, 5 \mathrm{mg} \mathrm{g}^{-1}$ for $\mathrm{S} 4$ $(2 \mathrm{H})$ after $5 \mathrm{~min}$. These results clearly indicate an improved performance of the $1 \mathrm{~T}$ rich samples over $2 \mathrm{H}$ and $3 \mathrm{R}$ samples. 

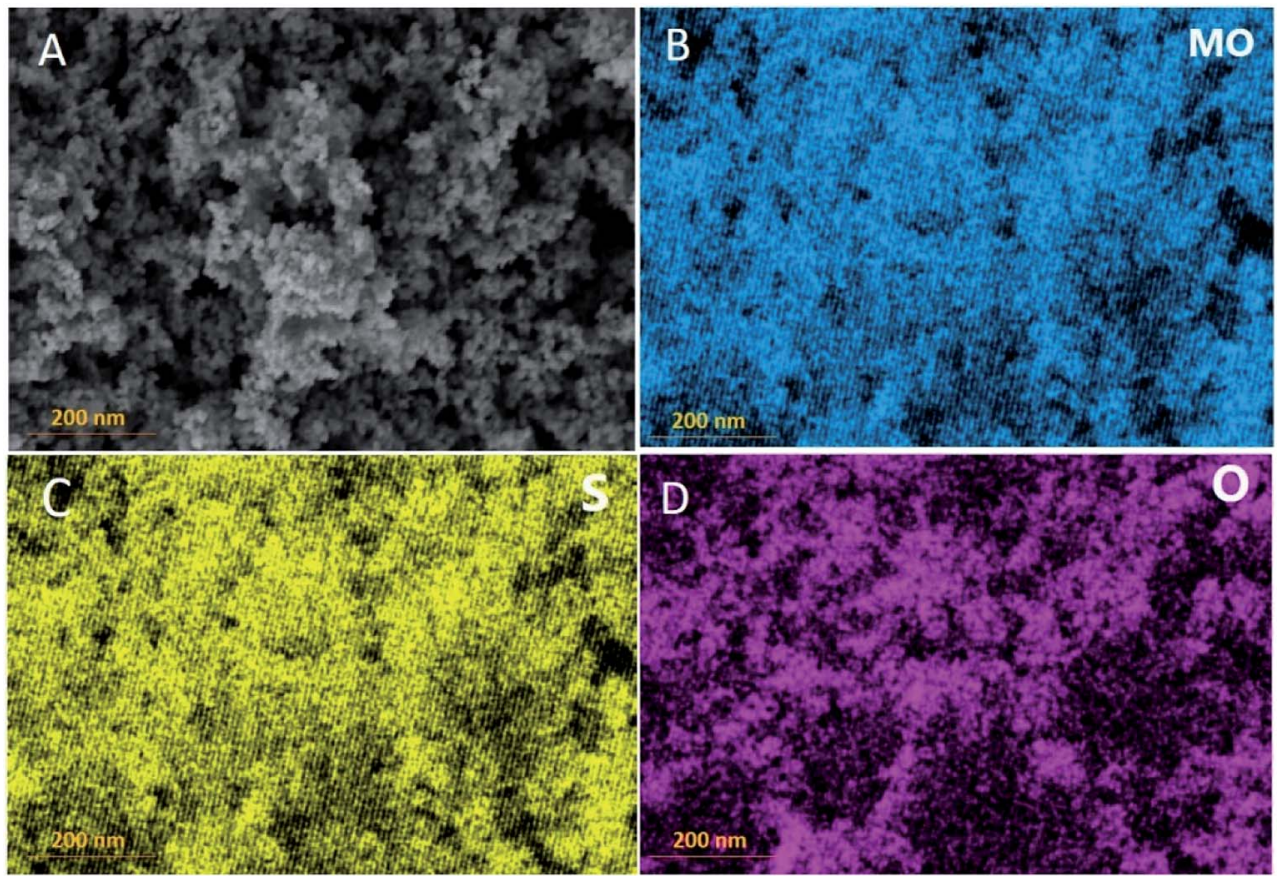

Fig. 1 (A) SEM image of the micro-flowers $\mathrm{MoS}_{2}$ nanosheets, (B-D) EDS elemental mapping of the MoS 2 nanosheets.

We investigated the adsorption selectivity of S1 towards different cationic (MB, RhB) and anionic (MO) dyes. The adsorption experiment was carried out for $120 \mathrm{~min}$ using
$100 \mathrm{ppm}$ dye solutions. The results show a much higher removal percent (adsorption capacity) of cationic dyes; MB, 99\% (201 $\mathrm{mg} \mathrm{g}^{-1}$ ), and $\mathrm{RhB}, 77 \%\left(160 \mathrm{mg} \mathrm{g}^{-1}\right)$ as compared to


Fig. 2 (A) Nitrogen adsorption-desorption isotherms, (B) zeta potential of S1 at different pH values, (C) particle size distribution of S1, S2 and S4 aqueous dispersions. 

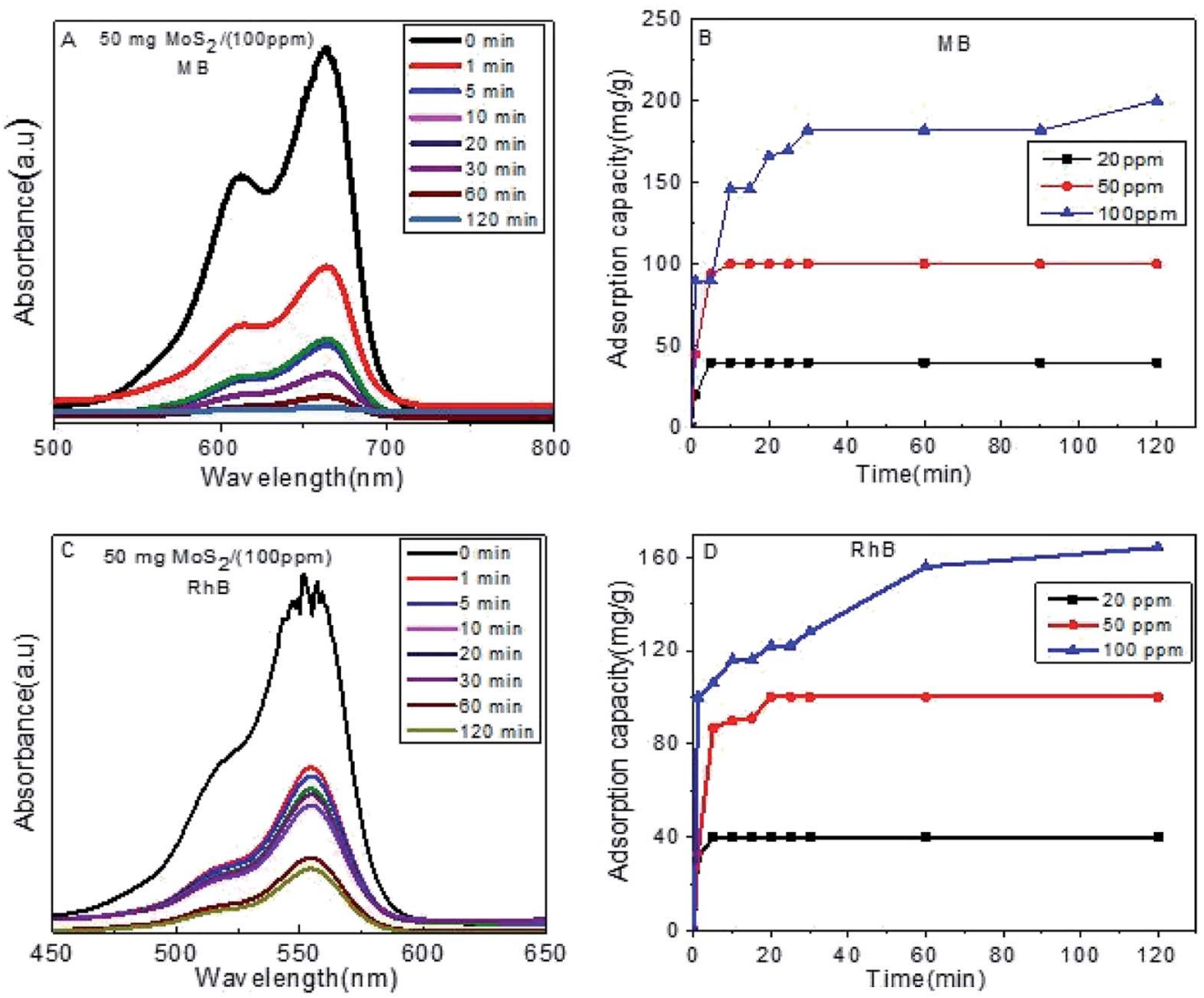

Fig. 3 (A) Absorption efficiency of MB on S1, (B) adsorption capacity for MB, (C) absorption efficiency of RhB on S1, (D) adsorption capacity for RhB.
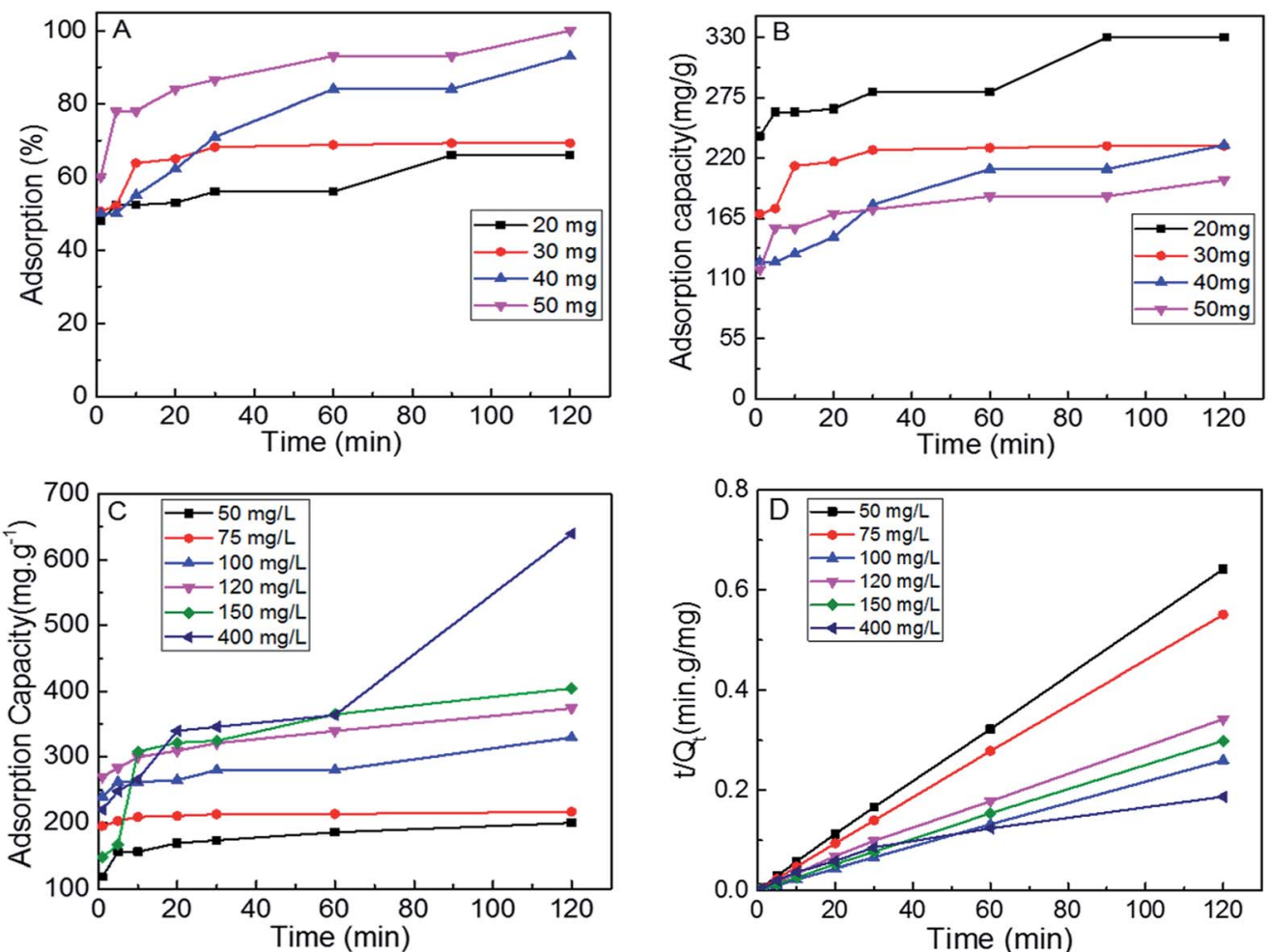

Fig. 4 (A and B) adsorption performance of different doses of S1 for MB aqueous solution, adsorption capacity (C) and pseudo second order model fits (D) of S1 at different dye concentrations. 
Table 1 Parameters of different isotherms for adsorption of MB onto S1



anionic (MO), 23\% (50 $\mathrm{mg} \mathrm{g}^{-1}$ ) (Fig. SI.4A and $\mathrm{B} \dagger$ ). These results are in good agreement with the negative surface charge indicated by the zeta potential measurements (Fig. 2C). They are also in good agreement with the previous reports that indicated a greater affinity of $\mathrm{MoS}_{2}$ sorbents towards cationic dyes. . $^{24,25,48,55,56}$

To evaluate the adsorption capacity of as-prepared S1 towards $\mathrm{MB}$ and $\mathrm{RhB}$, a $50 \mathrm{mg}$ dose was added to aqueous solution of different concentrations $(20 \mathrm{ppm}, 50 \mathrm{ppm}$ and 100 ppm) (Fig. 3). Complete removal was obtained after $120 \mathrm{~min}$ with an improved capacity for MB than RhB, which could be attributed to its smaller molecular size.

In order to determine the optimum conditions to conduct further adsorption studies, the S1 dosage was varied from $50 \mathrm{mg}$ to $20 \mathrm{mg}$. Fig. $4 \mathrm{~A}$ and $\mathrm{B}$ show the percent adsorption and adsorption capacity of the $\mathrm{S} 1 \mathrm{for} \mathrm{MB}(100 \mathrm{ppm})$ at varying
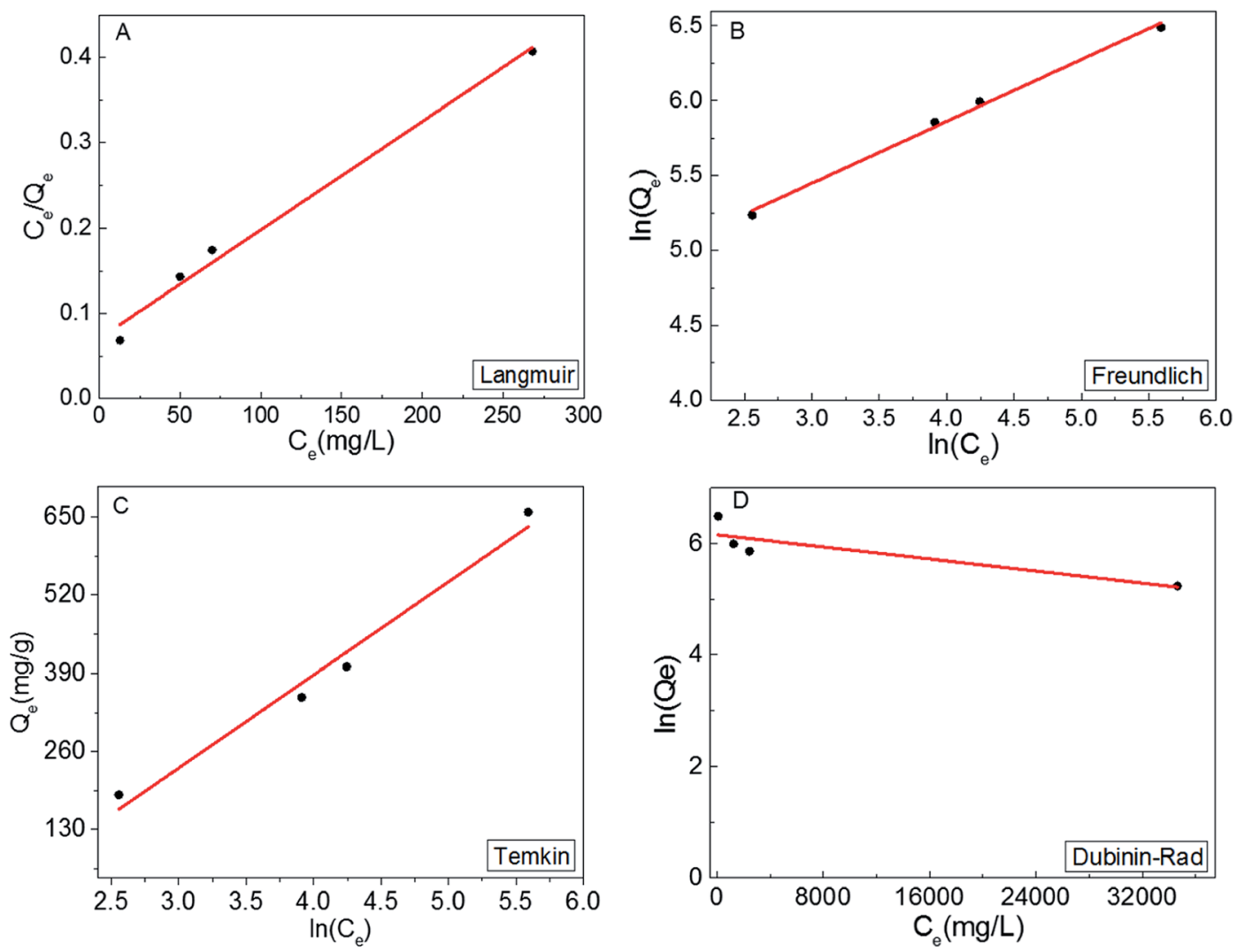

Fig. 5 Langmuir (A), Freundlich (B), (C) Temkin and (D) Dubinin-Rad isotherm curves fitting for MB adsorption onto S1. 
adsorption times. As the $\mathrm{MoS}_{2}$ dosage decreased from 50 to $20 \mathrm{mg}$, the adsorption capacities increased from $200 \mathrm{mg} \mathrm{g}^{-1}$ to $330 \mathrm{mg} \mathrm{g}^{-1}$. When the dye concentration was further increased up to $400 \mathrm{mg} \mathrm{L}^{-1}$, adsorption capacity of $652 \mathrm{mg} \mathrm{g}^{-1}$ was achieved (Fig. 4C).

The kinetics of the adsorption process was investigated by fitting the data to different kinetic models including pseudo first and second order models. Such models provide detailed information on the adsorption mechanism and the type of adsorption processes involved, including diffusion control, chemical reaction, and mass transport processes.
The kinetics studies for MB onto S1 was investigated using pseudo-first order and pseudo-second order, which can be expressed as: ${ }^{57}$

$$
\begin{gathered}
\ln \left(q_{\mathrm{e}}-q_{t}\right)=\ln q_{\mathrm{e}}-K_{1} t \\
\frac{t}{q_{t}}=\frac{1}{K_{2} q_{\mathrm{e}}^{2}}+\left(\frac{1}{q_{\mathrm{e}}}\right) t
\end{gathered}
$$

where $K_{1}, K_{2}$ are the pseudo-first and pseudo-second order rate constants $\left(\mathrm{g} \mathrm{mg}^{-1} \mathrm{~min}^{-1}\right) . q_{t}$ and $q_{\mathrm{e}}$ are the amounts adsorbed at time $t$ and at equilibrium $\left(\mathrm{mg} \mathrm{g}^{-1}\right)$ respectively. Our experimental data were fit against pseudo-first and
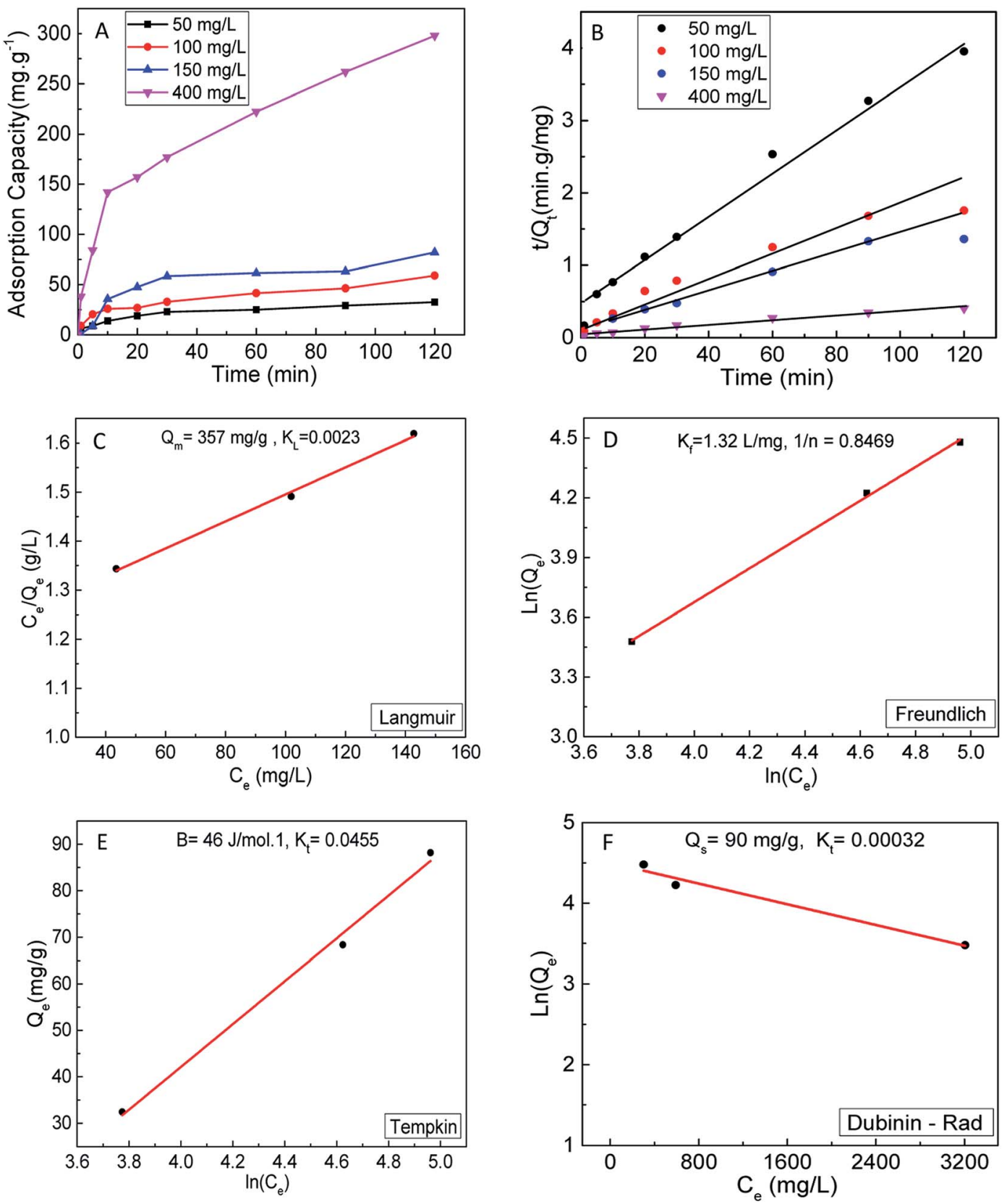

Fig. 6 Adsorption performance of S2; (A) adsorption performance of different concentration of MoS 2 for MB aqueous solution, (B) pseudo second order model fits, (C) Langmuir (D), Freundlich (E) Temkin and (F) Dubinin-Radushkevich isotherm curve fitting for MB adsorption onto S2. 
Table 2 Adsorption capacity of recent reports on $\mathrm{MoS}_{2}$ and $\mathrm{MoS}_{2}$-based materials

\begin{tabular}{|c|c|c|c|c|}
\hline Materials & Phase & $\begin{array}{l}\text { Adsorption capacity } \\
\left(\mathrm{mg} \mathrm{g}^{-1}\right)\end{array}$ & Dye & Ref. \\
\hline $\mathrm{MoS}_{2}$ & Hexagonal & 146.43 & MB & 21 \\
\hline $\mathrm{MoS}_{2}$ & Hexagonal & 499 & MB & 29 \\
\hline $\mathrm{MoS}_{2}$ & Hexagonal & $\begin{array}{l}208 \\
291\end{array}$ & $\begin{array}{l}\text { MB } \\
\text { RhB }\end{array}$ & 50 \\
\hline $\mathrm{MoS}_{2}$ & Hexagonal & 343.74 & MB & 61 \\
\hline g-MoS ${ }_{2}$-decorated biochar & Hexagonal & 249.45 & $\begin{array}{l}\text { Tetracycline } \\
\text { hydrochloride (TC) }\end{array}$ & 62 \\
\hline $\mathrm{Ni} / \mathrm{MoS}_{2}$ & Cubic & 277.77 & Congo red (CR) & 22 \\
\hline $\mathrm{MoS}_{2}$ & Hexagonal & 161.29 & Crystal violet dye (CV) & 63 \\
\hline $\mathrm{MoS}_{2}$ & Hexagonal & 49.2 & $\mathrm{RhB}$ & 7 \\
\hline
\end{tabular}

second order. Fig. SI. $5 \dagger$ shows that the pseudo-first-order didn't give a good fit for the experimental data. $R^{2}$ was very low (0.5519) and $q_{\mathrm{e}}$ was $445 \mathrm{mg} \mathrm{g}^{-1}$ for $400 \mathrm{mg} \mathrm{L}^{-1}$ dye which was far below the experimental value of $q_{\mathrm{e}}\left(652 \mathrm{mg} \mathrm{g}^{-1}\right)$. As shown in Fig. 4D, acceptable correlation was only observed for the pseudo-second order. The fit resulted in $q_{\mathrm{e}}$ values (e.g. $636 \mathrm{mg} \mathrm{g}^{-1}$ at $400 \mathrm{mg} \mathrm{L}^{-1}$ dye, $c f$. Table 1) was in excellent agreement with the experimental value $\left(652 \mathrm{mg} \mathrm{g}^{-1}\right)$. These collective results indicated that the adsorption process, to large extent depends on the surface active sites induced by the $1 \mathrm{~T}$ interfaces. ${ }^{58}$

\subsection{Isotherms}

In order to obtain a deeper insight on the nature of the adsorption layer and the distribution of the active sites on the sorbent surface, the adsorption data were fit to the following isotherms:

Langmuir isotherm which is expressed as: ${ }^{59}$

$$
\begin{aligned}
& \frac{C_{\mathrm{e}}}{q_{\mathrm{e}}}=\frac{1}{K_{\mathrm{L}} Q_{0}}+\frac{C_{\mathrm{e}}}{Q_{0}} \\
& R_{\mathrm{L}}=\frac{1}{\left(1+K_{\mathrm{L}} C_{0}\right)}
\end{aligned}
$$

where $Q_{0}$ and $K_{\mathrm{L}}$ are Langmuir constants. $C_{0}$ and $R_{\mathrm{L}}$ are the intimal concentration and separation factor. The correlation coefficient $R^{2}(0.9899)$ indicates that the adsorption process fits Langmuir model (Fig. 5A) with a maximum adsorption capacity $\left(Q_{0}\right)$ of $787 \mathrm{mg} \mathrm{g}^{-1}$ (Table 1). The separation factor $R_{\mathrm{L}}$ is between 0 and 1 , which indicates that the adsorption process is quite favourable.
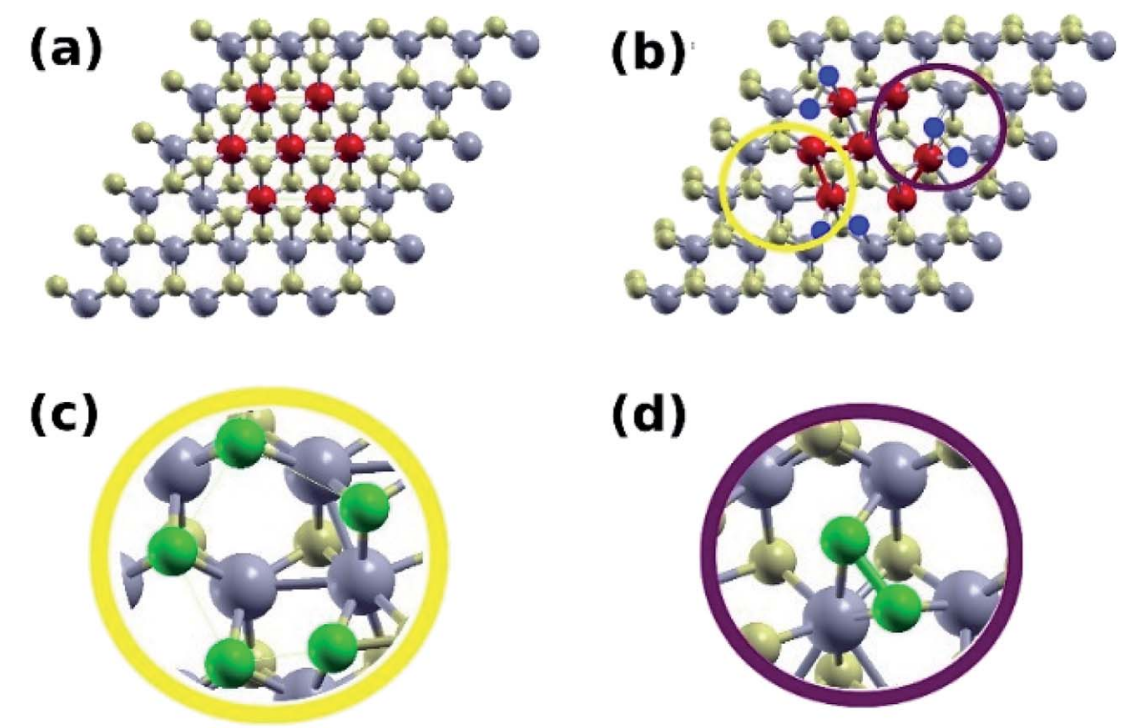

Fig. 7 (a) The $6 \times 6$-unit cell of an unrelaxed $\mathrm{MoS}_{2} 1 \mathrm{~T} / 2 \mathrm{H}$ mixed phase system where red Mo atoms indicate the $1 \mathrm{~T}$ phase. (b) Unit cell after relaxation. The yellow circle indicates a region with no $S$ atoms. The purple circle surrounds bonded $S$ atoms. (c and d) $A$ zoom-in on the two aforementioned regions, with the $\mathrm{S}$ atoms shown in green. 
(a)
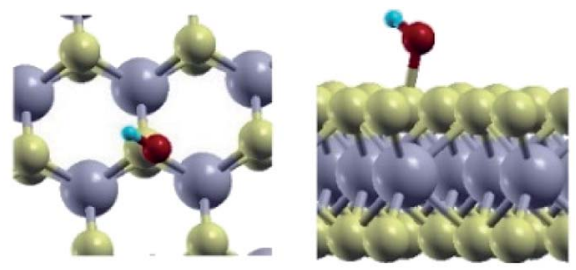

(b)
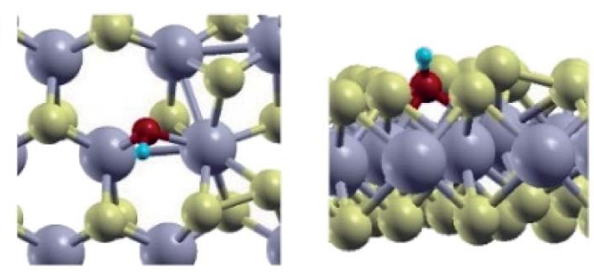

(c)
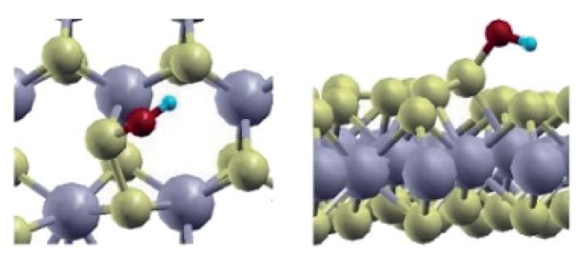

Fig. 8 (a) Top and side views of the $\mathrm{OH}$ group adsorbed at the $\mathrm{S}$ site of the pure $2 \mathrm{H}$ phase. (b) Top and side views of the $\mathrm{OH}$ group adsorbed at one of the Mo atoms at the boundary between the $2 \mathrm{H}$ and $1 \mathrm{~T}$ phases. (c) Top and side views of the $\mathrm{OH}$ group adsorbed at a $\mathrm{S}$ site at the boundary between the $2 \mathrm{H}$ and $1 \mathrm{~T}$ phases.

Freundlich isotherm model ${ }^{30}$ was used to evaluate the heterogeneity of the sorbent surface and can be expressed as follow: (a)
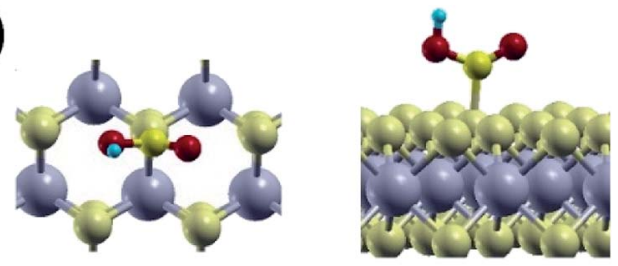

(b)



(c)



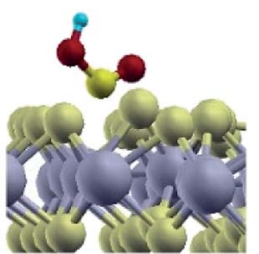

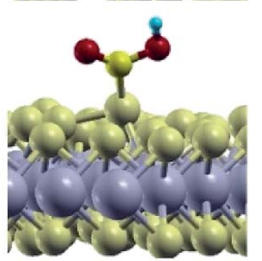

Fig. 9 (a) Top and side views of the $\mathrm{COOH}$ group adsorbed the $\mathrm{S}$ site of the pure $2 \mathrm{H}$ phase. (b) Top and side views of the $\mathrm{COOH}$ group adsorbed at one of the Mo atoms at the boundary between the $2 \mathrm{H}$ and $1 \mathrm{~T}$ phases. (c) Top and side views of the $\mathrm{COOH}$ group adsorbed at a $\mathrm{S}$ site at the boundary between the $2 \mathrm{H}$ and $1 \mathrm{~T}$ phases.

$$
\ln q_{\mathrm{e}}=\ln K_{\mathrm{F}}+\frac{1}{n} \ln C_{\mathrm{e}}
$$

where $K_{\mathrm{F}}$ is adsorption capacity at unit concentration and $1 / n$ is adsorption intensity. The plot of Freundlich model is shown in Fig. 5B. The $1 / n$ value of 0.4129 indicates a favourable adsorption process. ${ }^{\mathbf{5 8}}$

Temkin isotherm model can be expressed as follows:

$$
\begin{gathered}
q_{\mathrm{e}}=B_{1} \ln K_{\mathrm{T}}+B_{\mathrm{T}} \ln C_{\mathrm{e}} \\
B_{1}=\frac{R T}{b}
\end{gathered}
$$

where $K_{\mathrm{T}}$ is the equilibrium binding constant $\left(\mathrm{L} \mathrm{mg}^{-1}\right)$, and $B_{1}$ is related to the heat of adsorption. $T$ is the absolute temperature in $K, R$ is the universal gas constant. The high correlation coefficient (Fig. 5C) implies that the heat of adsorption of all the dye molecules decreases with increasing coverage.

For Dubinin-Radushkevich isotherm model: ${ }^{59}$

$$
\begin{gathered}
\ln q_{\mathrm{e}}=\ln Q_{\mathrm{s}}-K \varepsilon^{2} \\
\varepsilon=R T \ln \left(1+\frac{1}{C_{\mathrm{e}}}\right)
\end{gathered}
$$

where, $K$ is a constant related to the adsorption energy, $Q_{\mathrm{s}}$ is the theoretical saturation capacity and $\varepsilon$ is the Polanyi potential. This model describes the sorbent characteristics and free energy transported from the molecules to the surface, however, a poor correlation was observed (Table 1). The plot of DubininRadushkevich model was shown in Fig. 5D.

It can be concluded from the above results that the high correlation coefficient to Langmuir, Freundlich and Temkin isotherms suggest that several sorption mechanisms are involved. ${ }^{58}$ Moreover, the obtained results revelled that the surface of $\mathrm{MoS}_{2}$ exhibits a blend of heterogenous and homogenous active sites, and the overall rate of adsorption of MB on $\mathrm{MoS}_{2}$ surface was achieved by the two isotherm mechanisms.

To further investigate the role of surface-active sites in the adsorption process, the adsorption kinetics and isotherms of $\mathrm{S} 2$ were also investigated. The adsorption kinetics are shown in Fig. 6A and $\mathrm{B}$, which indicates that the experimental data are fit with the pseudo-second-order model. The adsorption data were fit to the same isotherm models (Fig. 6C-F). The results clearly show a lower adsorption capacity $\left(357 \mathrm{mg} \mathrm{g}^{-1}\right)$

Table 3 Adsorption energies and bond lengths of the $\mathrm{OH}$ and $\mathrm{COOH}$ groups at different adsorption sites

\begin{tabular}{llll}
\hline $\mathrm{OH}$ & $E_{\mathrm{b}}(\mathrm{eV})$ & $\mathrm{O}-\mathrm{S}(\AA)$ & O-Mo $(\AA)$ \\
\hline $2 \mathrm{H}$ & 1.26 & 1.79 & - \\
1T/2H_S & 2.66 & 1.67 & - \\
1T/2H_Mo & 2.95 & - & 2.09 \\
\hline COOH & $E_{\mathrm{b}}(\mathrm{eV})$ & $\mathrm{C}-\mathrm{S}(\AA)$ & C-Mo $(\AA)$ \\
\hline 2H & 0.20 & 1.87 & - \\
1T/2H_S & 1.60 & 1.89 & - \\
1T/2H_Mo & 0.08 & - & 2.68
\end{tabular}



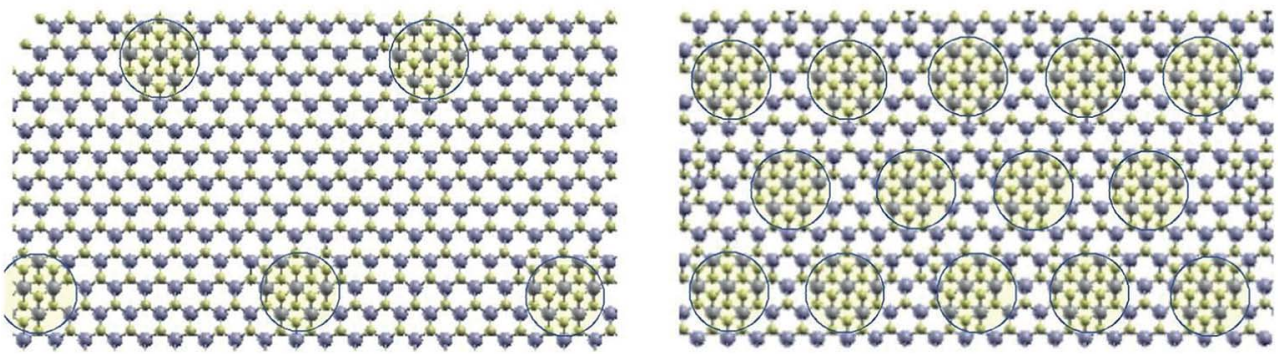

Fig. 10 Schematic description of the density of $1 T$ defects in both cases (20\% and $70 \%)$.

as compared to S1. This observation can be correlated to the less active surface in S2 due to the smaller content of $1 \mathrm{~T}$ phase ( 20\%).

Table 2 lists most of recent reports done on the dye adsorption using $\mathrm{MoS}_{2}$. It can be noticed that our materials have shown the highest adsorption capacity for MB. In addition, in all these studies the control over the materials phase was missing and/or unknown.

\subsection{Computational studies}

In this part, computational studies of the adsorption properties of the hybrid $\mathrm{MoS}_{2}$ structure was carried out with the aim to deeply understand the role of $1 \mathrm{~T}$ active sites as well as to correlate the results with the experimental findings. Defects, edges, and other structural alterations in the $\mathrm{MoS}_{2}$ lattice lead to active sites that can be utilized for various applications. Adsorption of dyes on $\mathrm{MoS}_{2}$ nanosheets is mediated by the hydroxide and carboxyl groups bound to the $\mathrm{MoS}_{2}$ surface. ${ }^{21,50}$ It is therefore desirable to explore whether the mixed phase enhances the binding of these groups to its surface. Two $\mathrm{MoS}_{2}$ systems were constructed, a pure $2 \mathrm{H}$ phase (S4), and a mixed $1 \mathrm{~T} / 2 \mathrm{H}$ phase (S1). The Mo atoms of the $1 \mathrm{~T}$ region were marked in red (Fig. 7). Upon structural relaxation, the grain boundary found to have regions where displaced $\mathrm{S}$ atoms leave some Mo atoms more exposed to adsorbents compared to corresponding atoms in the pure $2 \mathrm{H}$ phase (Fig. 7b and c, yellow circle). Furthermore, there were sites with bonded S atoms (Fig. 7b and d, purple circle). Such structural defects present at the $1 \mathrm{~T} / 2 \mathrm{H}$ grain boundary were the focus of our computational investigation.

Fig. 8 shows the hydroxide group adsorbed on the pure $2 \mathrm{H}$ phase of $\mathrm{MoS}_{2}$ (Fig. 8a), and the mixed 1T/2H phase (Fig. 8b and $\mathrm{c}$ ). We find that the group adsorbs to the $\mathrm{S}$ site of the pure $2 \mathrm{H}$ phase with a binding energy of $1.26 \mathrm{eV}$, with an $\mathrm{O}-\mathrm{S}$ distance of $1.79 \AA$. On the contrary, the hydroxide group adsorbs to mixed phase at the Mo site with a significantly higher energy of $2.95 \mathrm{eV}$, and an O-Mo distance of $2.09 \AA$, and on the S-S bonded site with an energy of $2.67 \mathrm{eV}$, and an $\mathrm{O}-\mathrm{S}$ distance of $1.67 \AA$.

The mixed phase is also superior to the pure one in adsorbing the carboxyl group (Fig. 9), with binding energy of $1.60 \mathrm{eV}$ at the S-S site, and a C-S distance of $1.89 \AA$. On the contrary, the binding energy with the pure $2 \mathrm{H}$ phase is only $0.2 \mathrm{eV}$. Binding at the Mo site of the mixed phase is weak in this case because of the electrostatic size of the carboxyl group. Our results are summarized in Table 3.

Although we have not taken van de Waals (vdW) interactions into consideration, their effect will not significantly change our findings. vdW corrections are expected to enhance the adsorption of hydroxide and carboxyl groups on the $\mathrm{MoS}_{2}$ surface, typically by $\sim 0.5 \mathrm{eV}$, which will preserve the superiority of the $1 \mathrm{~T}$ boundary regions for adsorbing the functional groups.

The density of the structural defects at the $1 \mathrm{~T}$ grain boundaries is proportional to the perimeter of the $1 \mathrm{~T}$ region (Fig. 10). Therefore, and assuming a fixed typical $1 \mathrm{~T}$ size, increasing the 1T concentration will be accompanied by an increase in the adsorption capacity of the mixed phase; an increase that varies as the square root of the concentration. This is in great agreement with the maximum adsorption capacities obtained for S1 and S2. As such, an estimate of the ratio between the adsorption capacities of the $20 \%$ and $70 \%$ samples is:

$$
\frac{\sqrt{70}}{\sqrt{20}}=1.87
$$

which agrees with our experimental value of this ratio $=1.8$.

\section{Conclusions}

Hybrid phases of $\mathrm{MoS}_{2}$ nanosheets were prepared via hydrothermal method at different conditions. The adsorption performance for the MO, MB and RhB were investigated. The results indicated that the dependence of adsorption performance on $1 \mathrm{~T}$ phase level in $\mathrm{MoS}_{2}$ nanosheets. The superior adsorption selectivity for $\mathrm{MB}$ and $\mathrm{RhB}$ dyes over $\mathrm{MoS}_{2}$ nanosheets is worthy noted rather than MO dye. Kinetic studies revealed that adsorption capacity of $\mathrm{MB}$ and RhB showed a wellfitting with the second order model with high correlation coefficient $R^{2}$. The adsorption data were fit to different isotherm models, in which the Langmuir model provided the well fit to the experimental data with maximum adsorption capacity of $787 \mathrm{mg} \mathrm{g}^{-1}$ for MB. Density functional theory calculations indicate a significantly improved adsorption performance of the 
$1 \mathrm{~T} / 2 \mathrm{H}-\mathrm{MoS}_{2}$ mixed phase, where the defects occurring at the $1 \mathrm{~T} /$ $2 \mathrm{H}$ grain boundaries bind the chemical groups mediating the dye adsorption more strongly.

\section{Conflicts of interest}

There are no conflicts to declare.

\section{Acknowledgements}

This work was partially supported by grants funded by Science, Technology and Development Fund (STDF, Egypt) and the ArabGerman Young Academy of Sciences and Humanities (AGYA), Germany. A. Maarouf would like to acknowledge the use of the resources of the Supercomputing Laboratory at KAUST, Saudi Arabia.

\section{References}

1 J. Wang, S. Han, W. Zhang, D. Liang, Y. Li, X. Zhao and R. Wang, Int. J. Hydrogen Energy, 2013, 38, 14631-14637.

2 X. Mi, G. Huang, W. Xie, W. Wang, Y. Liu and J. Gao, Carbon, 2012, 50, 4856-4864.

3 N. A. Travlou, G. Z. Kyzas, N. K. Lazaridis and E. A. Deliyanni, Langmuir, 2013, 29, 1657-1668.

4 Y. Yu, J. Wan, Z. Yang and Z. Hu, J. Colloid Interface Sci., 2017, 502, 100-111.

5 M. R. Saber, G. Khabiri, A. A. Maarouf, M. Ulbricht and A. S. Khalil, $R S C$ Adv., 2018, 8, 26364-26370.

6 R. Yang, J. Wang, W. Liu, Y. Zhang, H. Wang, S. Liu, Y. Guo and S. Chen, ChemistrySelect, 2017, 2, 8643-8649.

7 X. Wang, J. Ding, S. Yao, X. Wu, Q. Feng, Z. Wang and B. Geng, J. Mater. Chem. A, 2014, 2, 15958-15963.

8 B. A. Ali, O. I. Metwalli, A. S. Khalil and N. K. Allam, ACS Omega, 2018, 3, 16301-16308.

9 B. A. Ali, A. M. Omar, A. S. G. Khalil and N. K. Allam, ACS Appl. Mater. Interfaces, 2019, DOI: 10.1021/acsami.9b11444.

10 Z. Zhang, P. Yang, M. Hong, S. Jiang, G. Zhao, J. Shi, Q. Xie and Y. Zhang, Nanotechnology, 2019, 30, 182002.

11 U. Krishnan, M. Kaur, K. Singh, M. Kumar and A. Kumar, Superlattices Microstruct., 2019, 128, 274.

12 Y. Yu, G.-H. Nam, Q. He, X.-J. Wu, K. Zhang, Z. Yang, J. Chen, Q. Ma, M. Zhao, Z. Liu, F.-R. Ran, X. Wang, H. Li, X. Huang, B. Li, Q. Xiong, Q. Zhang, Z. Liu, L. Gu, Y. Du, W. Huang and H. Zhang, Nat. Chem., 2018, 10, 638-643.

13 A. L. Friedman, A. T. Hanbicki, F. K. Perkins, G. G. Jernigan, J. C. Culbertson and P. M. Campbell, Sci. Rep., 2017, 7, 3836.

14 D. Voiry, H. Yamaguchi, J. Li, R. Silva, D. C. Alves, T. Fujita, M. Chen, T. Asefa, V. B. Shenoy and G. Eda, Nat. Mater., 2013, 12, 850.

15 M. Li, D. Wang, J. Li, Z. Pan, H. Ma, Y. Jiang and Z. Tian, $R S C$ Adv., 2016, 6, 71534-71542.

16 R. Abinaya, J. Archana, S. Harish, M. Navaneethan, S. Ponnusamy, C. Muthamizhchelvan, M. Shimomura and Y. Hayakawa, RSC Adv., 2018, 8, 26664-26675.

17 M. A. Lukowski, A. S. Daniel, F. Meng, A. Forticaux, L. Li and S. Jin, J. Am. Chem. Soc., 2013, 135, 10274-10277.
18 M. Acerce, D. Voiry and M. Chhowalla, Nat. Nanotechnol., 2015, 10, 313.

19 S. Bai, L. Wang, X. Chen, J. Du and Y. Xiong, Nano Res., 2015, 8, 175-183.

20 K. Chang, X. Hai, H. Pang, H. Zhang, L. Shi, G. Liu, H. Liu, G. Zhao, M. Li and J. Ye, Adv. Mater., 2016, 28, 10033-10041.

21 X.-Q. Qiao, F.-C. Hu, F.-Y. Tian, D.-F. Hou and D.-S. Li, RSC $A d v .$, 2016, 6, 11631-11636.

22 H. Song, S. You and X. Jia, J. Mater. Sci.: Mater. Electron., 2016, 27, 10841-10848.

23 A. T. Massey, R. Gusain, S. Kumari and O. P. Khatri, Ind. Eng. Chem. Res., 2016, 55, 7124-7131.

24 B. Xu, Y. Li, G. Wang, D. Zhao, K. Pan, B. Jiang, W. Zhou and H. Fu, Dalton Trans., 2015, 44, 6224-6228.

25 H. J. Song, S. You, X. H. Jia and J. Yang, Ceram. Int., 2015, 41, 13896-13902.

26 H. Song, S. You and X. Jia, Appl. Phys. A: Mater. Sci. Process., 2015, 121, 541-548.

27 Y. Zhao, X. Zhang, C. Wang, Y. Zhao, H. Zhou, J. Li and H. Jin, Appl. Surf. Sci., 2017, 412, 207-213.

28 K.-h. HU, D.-f. ZHAO and J.-s. LIU, Trans. Nonferrous Met. Soc. China, 2012, 22, 2484-2490.

29 H. Li, F. Xie, W. Li, B. D. Fahlman, M. Chen and W. Li, RSC Adv., 2016, 6, 105222-105230.

30 H. Xie and X. Xiong, J. Environ. Chem. Eng., 2017, 5, 11501158.

31 L. Ye, H. Xu, D. Zhang and S. Chen, Mater. Res. Bull., 2014, 55, 221-228.

32 F. Zhao, Y. Rong, J. Wan, Z. Hu, Z. Peng and B. Wang, Nanotechnology, 2018, 29, 105403.

33 A. Manikandan, P. R. Ilango, C.-W. Chen, Y.-C. Wang, Y.-C. Shih, L. Lee, Z. M. Wang, H. Ko and Y.-L. Chueh, J. Mater. Chem. A, 2018, 6, 15320-15329.

34 L. Kong, A. Enders, T. S. Rahman and P. A. Dowben, J. Phys.: Condens. Matter, 2014, 26, 443001.

35 G. Ersan, O. G. Apul, F. Perreault and T. Karanfil, Water Res., 2017, 126, 385-398.

36 B. Szczęśniak, J. Choma and M. Jaroniec, Adv. Colloid Interface Sci., 2017, 243, 46-59.

37 F. R. Bagsican, A. Winchester, S. Ghosh, X. Zhang, L. Ma, M. Wang, H. Murakami, S. Talapatra, R. Vajtai, P. M. Ajayan, J. Kono, M. Tonouchi and I. Kawayama, Sci. Rep., 2017, 7, 1774.

38 L. Chen, E. E. L. Tanner and R. G. Compton, Phys. Chem. Chem. Phys., 2017, 19, 17521-17525.

39 F. Ferreira, A. Carvalho, Í. J. M. Moura, J. Coutinho and R. M. Ribeiro, J. Phys.: Condens. Matter, 2017, 30, 035003.

40 C. González, B. Biel and Y. J. Dappe, Phys. Chem. Chem. Phys., 2017, 19, 9485-9499.

41 S.-Y. Cho, S. J. Kim, Y. Lee, J.-S. Kim, W.-B. Jung, H.-W. Yoo, J. Kim and H.-T. Jung, ACS Nano, 2015, 9, 9314-9321.

42 S. S. Chou, N. Sai, P. Lu, E. N. Coker, S. Liu, K. Artyushkova, T. S. Luk, B. Kaehr and C. J. Brinker, Nat. Commun., 2015, 6, 8311.

43 D. Ghim, Q. Jiang, S. Cao, S. Singamaneni and Y.-S. Jun, Nano energy, 2018, 53, 949-957. 
44 L. Jiang, S. Zhang, S. A. Kulinich, X. Song, J. Zhu, X. Wang and H. Zeng, Mater. Res. Lett., 2015, 3, 177-183.

45 P. Giannozzi, S. Baroni, N. Bonini, M. Calandra, R. Car, C. Cavazzoni, D. Ceresoli, G. L. Chiarotti, M. Cococcioni, I. Dabo, A. Dal Corso, S. de Gironcoli, S. Fabris, G. Fratesi, R. Gebauer, U. Gerstmann, C. Gougoussis, A. Kokalj, M. Lazzeri, L. Martin-Samos, N. Marzari, F. Mauri, R. Mazzarello, S. Paolini, A. Pasquarello, L. Paulatto, C. Sbraccia, S. Scandolo, G. Sclauzero, A. P. Seitsonen, A. Smogunov, P. Umari and R. M. Wentzcovitch, J. Phys.: Condens. Matter, 2009, 21, 395502.

46 H. J. Monkhorst and J. D. Pack, Phys. Rev. B: Solid State, 1976, 13, 5188.

47 Z. Wu, B. Li, Y. Xue, J. Li, Y. Zhang and F. Gao, J. Mater. Chem. A, 2015, 3, 19445-19454.

48 H. Fan, R. Wu, H. Liu, X. Yang, Y. Sun and C. Chen, J. Mater. Sci., 2018, 53, 10302-10312.

49 N. Thi Xuyen and J. M. Ting, Chem.-Eur. J., 2017, 23, 1734817355.

50 S. Han, K. Liu, L. Hu, F. Teng, P. Yu and Y. Zhu, Sci. Rep., 2017, 7, 43599.

51 V. Gupta, O. Moradi, I. Tyagi, S. Agarwal, H. Sadegh, R. Shahryari-Ghoshekandi, A. Makhlouf, M. Goodarzi and A. Garshasbi, Crit. Rev. Environ. Sci. Technol., 2016, 46, 93118.
52 J. Fu, Z. Chen, M. Wang, S. Liu, J. Zhang, J. Zhang, R. Han and Q. Xu, Chem. Eng. J., 2015, 259, 53-61.

53 Z. Chen, J. Zhang, J. Fu, M. Wang, X. Wang, R. Han and Q. Xu, J. Hazard. Mater., 2014, 273, 263-271.

54 W. Zhang, X. Xiao, L. Zheng and C. Wan, Can. J. Chem. Eng., 2015, 93, 1594-1602.

55 X. Zhang, X. Liu, G. Liang, R. Li, H. Xu and B. Yan, J. Quant. Spectrosc. Radiat. Transfer, 2016, 168, 66-77.

56 T. Yan, N. Li, Z. Qiao, W. Li, H. Wang, Z. Jing, Y. Yu and Z. Jiang, J. Alloys Compd., 2019, 784, 256-265.

57 M. T. Yagub, T. K. Sen, S. Afroze and H. M. Ang, Adv. Colloid Interface Sci., 2014, 209, 172-184.

58 M. S. Embaby, S. D. Elwany, W. Setyaningsih and M. R. Saber, Chin. J. Chem. Eng., 2018, 26, 731-739.

59 Y. Chao, W. Zhu, X. Wu, F. Hou, S. Xun, P. Wu, H. Ji, H. Xu and H. Li, Chem. Eng. J., 2014, 243, 60-67.

60 A. Pal, T. K. Jana, T. Roy, A. Pradhan, R. Maiti, S. M. Choudhury and K. Chatterjee, ChemistrySelect, 2018, 3, 81-90.

61 Y. Li, H. Li, S. Zhou, H. Yang, F. Xie and W. Li, Res. Chem. Intermed., 2018, 44, 4353-4364.

62 Z. Zeng, S. Ye, H. Wu, R. Xiao, G. Zeng, J. Liang, C. Zhang, J. Yu, Y. Fang and B. Song, Sci. Total Environ., 2019, 648, 206-217.

63 S. A. Ansari, R. Kumar, M. Barakat and M. H. Cho, J. Mater. Sci.: Mater. Electron., 2018, 29, 7792-7800. 